\title{
Klasik Türk Şiirinde Bir Mûsikî Unsuru Olarak "Tîr/Ok"
}

\author{
Özlem DÜZLÜ*
}

$\ddot{\mathrm{O} z}$

Klasik Türk şiirinin kelime kadrosunda bulunan pek çok kelime birden fazla anlamıyla şiirlerde yer almıştır. Şairler bu tür kelimeleri kimi zaman yaygın olarak kullanılan anlamları dışında başka bir anlamıyla da şiir metinlerine alırken kimi zaman da birden fazla anlamını karşılayacak şekilde kullanmışlardır. "Tîr" ve onun Türkçe karşılığı olan "ok" da bu kelimeler arasındadır. Şiir metinlerinde genellikle bir silah unsuru olarak yer verilen bu kelimelerden "tîr"in "Utarit" anlamı da şairlerce rağbet görmüştür. Söz konusu kelimelerin şiir metinlerinde geçen bir başka anlamı da "keman, kemençe, rebap gibi sazları çalmaya yarayan alet (yay)"dır. Kelimelerin lûgatların büyük çoğunluğunda yer almayan bu anlamı, özellikle tevriye ve ihâm-1 tenasüp yoluyla oluşturulan çok anlamlı yapı içinde şairler için hüner gösterme vasıtası olurken klasik şiir okurunun/araştırmacısının gözünden kaçabilmektedir. "Tîrin/okun” bu farklı kullanımına dikkat çekmek üzere kaleme alınan bu makaleyle bahse konu kelimelerin yer aldığ 1 şiir metinlerinin daha doğru anlaşılmasına katkı sağlanması amaçlanmıştır. Ayrıca bir mûsikî unsuru olarak "tîrin/okun" şiir metinlerinde hangi özellikleriyle ve ne şekilde yer aldığı ortaya konmaya çalışılmıştır.

Anahtar Kelimeler: Tîr, ok, yay, mûsikî, klasik Türk şiiri

\footnotetext{
* Öğr. Gör. Dr., Sakarya Üniversitesi Rektörlük Türk Dili Bölümü, Sakarya, Türkiye. Elmek: oduzlu@sakarya.edu.tr https://orcid.org/0000-0001-9305-4371
} 


\title{
“Tîr/Ok" As A Musical Element In Classical Turkish Poetry
}

\begin{abstract}
Several words in the vocabulary of classical Turkish poetry have been included in poems with more than one meaning. Such words are sometimes used by poets with a meaning other than their central meaning, while they are sometimes used to correspond to multiple meanings. "Tîr" and its Turkish translation "ok" [arrow] are among these words. The "Utarit" [Mercury] meaning of "tîr", which is among these words that are included as weapon-like elements in poetry texts, has also gained attention from poets. Another meaning of the aforementioned words that is used in poetry texts is the tool that is used to play instruments such as "the violin, kemancha or rebab", a 'yay' [bow]. While this meaning of the words that is not included in most dictionaries is used as a way of showing talent by poets in a structure with multiple meanings that is created especially by means of double-entendre and 'ihâm-1 tenasüp', it may be overlooked by readers/researchers of classical poetry. With this paper which was written to describe the usage of this different meaning of the word "tîr/ok", it was aimed to contribute to a more accurate understanding poetry texts in which these words are found. It was also aimed to reveal with which aspects of it and in which forms "tîr/ok" as a musical element was included in poetry texts.
\end{abstract}

Keywords: Tîr, ok, bow, music, Classical Turkish Poetry 


\section{Extended Summary}

Several words in the vocabulary of classical Turkish poetry have been included in poems with more than one meaning. Such words are sometimes used with a meaning other than their central meaning, while they are sometimes used to correspond to multiple meanings. It makes it more difficult to correctly understand texts when poem analyses to be carried out neglect the meanings of a word that are outside its central meaning or those that have disappeared over time. In this context, it is needed to keep in mind the different meanings of several words used in classical Turkish poetry by considering their syntactic structure and characteristics related to literary arts. "Tîr" in Farsi and its Turkish translation "ok" (arrow) are among the words that a reader/researcher of classical Turkish poetry should approach carefully due to the usage of these words with meanings other than their popular meanings.

"Tîr" and "ok," as weapon-like elements, were associated in poetry texts with a loved one's elements of beauty, curse of a lover, their suffering and the pain of separation. The "Utarit" (the planet Mercury) meaning of "tîr", which is one of the words that are frequently used as a term of archery in poems with themes of archery competitions, is among the ways of usage that are frequently encountered in classical poetry. Other than these, one meaning of these words that are included in some poetry texts but not most is "yay" (a bow) which is used to play instruments like the "violin, kemancha and rebab." This meaning of these words got our attention as an element that may be overlooked by readers/ researchers of classical poetry especially in the multi-meaning poetic structures that are formed with double-entendres. This article, which aims to contribute to a more accurate understanding of texts by utilizing these usages of the words "tîr" and "ok" in classical Turkish poetry, also discusses with which characteristics and how these words in question have been included in classical poetry as musical elements. Examples of couplets, which were selected from among the couplets that were determined by scanning more than a hundred divans (poetry 
collections) written from the 14th century to the 19th century, are separately included under the titles of "tîr" and "ok". Under these titles, firstly all the meanings of these words that could be found in dictionaries are presented, and then, it is aimed to exactly determine the meaning that corresponds to a musical element by utilizing the texts where these words were included with their meaning "yay" (bow) or where this meaning was implied.

It was seen that the word "tîr" which is defined in the "Turkish and English Lexicon" as a "violin bow" was also used alongside kemancha and rebab in the examples that were studied. Additionally, the word "ok" which is defined in the "Compilation Dictionary" as a "kemancha bow" and in the "Turkish and English Lexicon" as a "violin bow" was used alongside words referring to either a violin or a kemancha in these examples. In this sense, it is understood that the words "tîr" and its Turkish translation "ok" have corresponded to bows for not only a violin of kemancha but also other string instruments such as a rebab or tanpura.

These words in the determined examples, as a musical element, were usually included through double-entendres, tenasüp / ihâm-1 tenasüp, comparisons and metaphors. When comparisons and metaphors which are arts in classical Turkish poetry based on likening have been used, "tîr/ok" have usually been likened to dimples, gaze, eyelashes, kebab skewers, arrowheads and nightingales as in most cases in classical Turkish poetry. In these likening relations that are formed, the aspect of likening is usually the magnificence/hurtfulness of the sound that it makes when it touches the strings of a musical instrument. In some cases, form-related likening was preferred (kebab skewers or eyelashes). As demonstrated by this article, also considering the meaning of "bow" for these words in textual analyses to be carried out will help a more accurate understanding of poetry texts. Additionally, with this study, it is demonstrated again that one needs to approach almost all words that are included in classical Turkish poetry texts carefully by considering the possibility that they have different meanings that might have been previously overlooked. 


\section{Giriş}

Klasik Türk şiirinin kelime kadrosunda, metinlerde birden fazla anlamıyla yer almış çok sayıda kelime bulunmaktadır. Klasik Türk şairleri bu tür kelimeleri kimi zaman yaygın olarak kullanılan anlamları dışında başka bir anlamıyla da şiir metinlerine alırken kimi zaman da kelimelerin birden fazla anlamına uygun bir yapı kurarak farklı anlam katmanlarına sahip metinler oluşturmuşlardır. Şairlerin bu tasarrufları dikkate alındığında bir kelimenin yaygın anlamı dışında kalan veya zamanla ortadan kalkmış anlamlarının göz ardı edilmesi ya da bilinmemesi şiir metinlerinin layıkıyla çözümlenebilmesini güçleştirmektedir. Böyle durumlarda klasik Türk şiiri okurlarını/araştırmacılarının beyit ya da bentlerin sözdizimsel yapı, edebî sanatlar gibi özelliklerini de dikkate alarak kelimelerin farklı anlam seçeneklerine yönelmeleri gerekir. Şiir metinlerinde sık karşılaşılan Farsça "tîr” ve onun Türkçe karşıllğı olan “ok” kelimeleri de yaygın anlamı dışındaki kullanımları dolayısıyla bazı beyitlerde okurun/araştırmacının dikkatle yaklaşması gereken kelimelerdendir.

"Tîr" ve "ok" kelimeleri klasik Türk şiirinde daha çok bir silah unsuru olarak sevgilinin bazı güzellik unsurlarına, ve âşı̆̆ın ızdırabını ifade etmek üzere, âşığın âhı, çektiği cefâ ve ayrılık derdine benzetilmiştir. Bu kullanımlarda zaman zaman mecaza dönüşen kelime özellikle ok atma müsabakalarını konu edinen manzumelerde de okçuluk terimi olarak sık kullanılmıştır. Ayrıca "tîr"in "Utarit" anlamı da şairlerin genellikle tevriye ve ihâm-1 tenasüp gibi sanatlar yoluyla iltifat ettikleri bir kullanım olarak karşımıza çıkmaktadır. ${ }^{1}$ Bunların dışında söz konusu kelimelerin şiir metinlerinde geçen fakat lûgatların büyük çoğunluğunda yer

1 Bir nükte okudur kim atar bu kemer anı

Şol tîr-i felek k’oldu dil-i çarhda peydâ Ahmed Paşa (Tarlan,1992: 43)

Gökyüzünün ortasında gürünür olan şu feleğin Utarit’i bir nükte okudur ki, onu bu kemer atar. 
almayan "keman, kemençe, rebap gibi sazları çalmaya yarayan alet (yay)" anlamı da vardır. "Tir" ve "ok" kelimelerinin, klasik Türk şiirinde "kemân"2, "kemâne”3 ve "çûb" kelimeleriyle de karşılanan, bu anlamı özellikle tevriyeli kullanımlarla oluşturulan çok anlamlı yapı içinde şairler için hüner gösterme vasıtası olurken klasik şiir okurunun/araştırmacısının gözden kaçırabildiği bir husus olarak dikkatimizi çekmiştir.

Bu makalede "tîr" ve "ok" kelimelerinin bir mûsikî terimi olarak "yay" anlamıyla klasik Türk şiirinde alışılmışın dışındaki kullanımlarına işaret edilerek bu kelimelerin yer aldığı şiir metinlerinin daha doğru anlaşılmasına katkı sağlanması amaçlanmıştır. Ayrıca bir mûsikî unsuru olarak tîrin/okun şiir metinlerinde hangi özellikleriyle ve ne şekilde yer aldığı ortaya konmaya çalışılmıştır. Makalede 14. yüzyıldan 19. yüzyıla kadar yazılmış yüzden fazla divanının taranması sonucunda tespit edilen beyitlerden seçilen örnekler "tîr" ve "ok" olmak üzere iki ayrı başlık altında verilmiştir.

\section{Tîr}

Klasik Türk şiiri metinlerinde çok sık karşılaşılan "tîr" kelimesinin bir mûsikî terimi olan "yay" anlamı dışında lûgatlarda tespit edilebilen anlamları şu şekildedir: 1. Ok. 2. Utarit. 3. Şiirde mahbûbenin kirpiği ve nazar1. 4. Karanlık. 5. Güz mevsimi. 6. Gök gürültüsü ve yıldırım 7. Tufan. 8. Fırtına. 9. Benzerleri içinde yüksek ve seçkin olan şey. 10. Top ve Tüfek Mermisi 11. Takat. 12. Kadir ve mertebe. 13. Dar. 14. Darlık, sıkıntı. 15. Ok yılanı. 16. Hurma Çiçeği. 17. Nergis. 18. Bez. 19. Elbise tirizi. 20. Öfke ve gazap. 21. Kahır. 22. Direk. 23. Doğru, müstakîm. 24. Hisse, nasip. 25. Bulanık. 26. Şemsî dördüncü ay. 27. Bir melek ismi. 28. Her Şemsî ayın on üçüncü günü. 29. Kı1, saç. 30. Bir cins beyaz parça (bez). 31. Nergis ve zerrinkadeh denilen çiçek. 32. Birbirine eşit olan iki

2 Zâg-1 gamlar bâm-1 sînemde perîşân oldular

Nâle tîrin saldugı gibi kemânından rebâb Ramazan Behiştî (Aydemir 2018: 124)

Rebap inleyiş okunu yayından saldığı gibi gam kargaları göğsümün çatısında perişan oldular.

3 Furûğ-1 nağme-i mansûru mâh-tâb eyler

Atarsa penbe-i râzı kemâne-i tanbûr Şeyh Gâlib (Okcu 2011: 393)

Tambur yayı sır pamuğunu atarsa mansurun nağmesinin ıșı̆̆ın mehtaba döndürür.

$4 \mathrm{Bu}$ ol demdir ki esbân-1 neberdin perçemin mutrıb

Koparup bend ede destindeki çûb-1 kemân üzre Nedîm (Macit 1997: 27)

Bu, çalgıcının savaş atlarının perçemini koparıp elindeki keman yayının üzerine bağladığı zamandır. 
nesne. 33. Sahra, çöl. 34. Tavus kuşuna benzeyen bir tür kuş. 35. İhtişam. 36. Güç, kuvvet. 37. Güvenlik. 38. Kılavuz, delil. 39. Yanmış, kor. 40. İplik. 41. Dicle Nehri. 42. Sebze Tarhı. 43. Ekilmiş bostanın bir bölümü. 44. Evlek. 45. Ekin sulamak için açılan ark. 46. Su kenarına yapılan set. 47. Pirinç tarlasının evleklerini ayıran sınır. 48. Tarla sınırlarını belirleyen set veya yol. ${ }^{5}$

Kelimenin tüm bu anlamları dışında sadece Sir James W. Redhouse’un “Turkish and English Lexicon"unda rastlanan "keman yayı" (Redhouse 2006: 618) anlamı da yer almaktadır. Ulaşılabilen müzik ve sanat terimleri sözlüklerinde de "tîr" kelimesine/maddesine rastlanamamıştır. Bununla birlikte kelimenin, bir mûsikî unsuru olarak yer aldığı ya da en azından bu anlamı da çağrıştırdığı tespit edilen beyitlerden yalnızca keman yayını değil; kemençe, rebap gibi sazları da çalmaya yarayan aleti/yayı karşıladığı anlaşılmaktadır.

“Tîr” kelimesinin mûsikî unsuru olarak klasik Türk şiirindeki kullanımına aşağıda verilen örnek beyitler şairlerin bu kelimeyi özellikle tevriye ve tenasüp/ ihâm-1 tenasüp sanatları için malzeme yaptığını göstermektedir. Yine bu örneklerde “tîr”, mûsikî unsuru olarak, teşbih ve istiare yoluyla gamze, bakış, kirpik, kebap şişi, temren ve bülbüle benzetilmiştir.

Nakl eder ehl-i dile tîr ü rübâbın sırrın

Ârif-i levh ü kalem Hazret-i Sultân Veled S Şeyh Gâlib (Okcu 2011: 91)

Satıh ve kalem/Tanrı bilgisi ve iradesinin bilgini Sultan Veled, gönül ehline rebap ve yayın sirrinı nakleder.

Klasik şiirin son büyük temsilcisi sayılan Şeyh Gâlib'in (ö. 1799) Mevlânâ Celâleddîn-i Rûmî'nin oğlu Sultan Veled (ö. 1312) hakkındaki yukarıdaki beytinde Sultan Veled'in gönül ehline rebap ve yayının sırrını, dolayısıyla da rebabın sesindeki sırrı naklettiği söylenmiştir. Sultan Veled'in rebap çalışını, Mevlevilikte rebabın önemini ve Mevlânâ'nın "Bizim rebabımızın altı gözlü olması dünyanın

5 Bu anlamlar için bkz.: Mütercim Âsım, Burhân-ı Katı, TDK Yayyınları, İstanbul 2009, s. 777-778.; F. Steingass, A Comprehensive Persian-English Dictionary, Çağrı Yayınları, İstanbul 2005, s. 340-341.; Ziya Şükûn, Gencinei Güftar Ferheng-i Ziya, MEB Yayınları, İstanbul 1984, C. I, s. 40-41.; Mehmet Kanar, Büyük Farsça-Türkçe Sözlük, Birim Yayınları, İstanbul 1993, s. 201.; İbrahim Olgun-Cemşit Drahşan, Farsça-Türkçe Sözlük, Murat Kitabevi, Ankara 2005, s. 100.; Sir James W. Redhouse, Lûgat-i Osmânîyye, Matbaa-i Âmire, İstanbul 1863, s. 111., Turkish And English Lexicon New Edition, Çağrı Yayınları, İstanbul 2006, s. 618.; Hüseyin Remzi, Lûgat-ı Remzî, Matbaa-i Hüseyin Remzi, İstanbul H. 1305, C. I, s. 358.; Şemseddin Sami, Kâmûs-ı Türkî, Çağrı Yayınları, İstanbul 2006, s. 456.; Ferit Devellioğlu, Osmanlıca-Türkçe Lûgat, Aydın Kitabevi, Ankara 1999, s. 1110. Yaşar Çağbayır, Ötüken Türkçe Sözlük, Ötüken Neşriyat, İstanbul 2007, C. V, s. 4832. 
altı yönünün sırlarını açıklamasındandır. Elif gibi olan teller de ruhların Allah ${ }^{\text {ee }}$ n elifi ile birlikte olduğunu gösterir” (Eflâkî 2006: 127; Uygun 2007: 117-126) şeklindeki sözlerini de akıllara getiren bu beyit "tîr" kelimesinin sadece "yay" anlamıyla kullanıldığı ender kullanımlardan biri olarak karşımıza çıkmaktadır.

Bak tîr-i gamzenin bile şimdi safayıla

Âmed şüd-i tereddüdü sîne kemânedir Şeyh Gâlib (Okcu 2011: 390)

Bak, şimdi gamze yayının/okunun bile neşeyle kararsız geliş gidişi sinekemanadır.

Şeyh Gâlib, gamzeyi keman yayı olarak tasavvur ettiği bu beytinde ise Mevlevî dergâhında gamze yayının bile sinekemana kararsız geliş gidişlerinin olduğunu söylemiştir. Beyitte "tîr" ve "kemân” kelimelerinin bir arada kullanılması ve klasik şiirde gamzenin sıklıkla oka benzetilmesi "tîr"in "ok" anlamını da ak1llara getirmektedir.

Nağmene tîr-i nigeh piş-rev olmakda meğer

Mutrıb ebrû da kemânınla hem-âheng midir Nedîm (Macit 1997: 287)

(Ey) çalgıcı! Meğer bakış yayı/oku nağmene peşrev olmakta, kaşın da kemanınla bir midir/aynı ahenkte midir?

Nedîm (ö. 1730), bu beytinde keman yayına benzettiği çalgıcının bakışının onun nağmelerine peşrev olması nedeniyle kaşının da kemanıyla bir olma ihtimalini sorgulamaktadır. Mutrib etrafinda kurgulanan bu beyitte "tîr" kelimesinin akla gelen ilk anlamı "keman yayı" olmakla birlikte "tîr-pîşrev-kemân" kelimelerinin okçulukla ilgili anlamları ve klasik Türk şiirindeki "bakış-tîr" ve "ebrû-keman" ilgisi beyti okçuluk ekseninde değerlendirmeyi de mümkün kılmaktadır.

Tîr-i nâle der-kemân ü bî-ser ü pâ sîne-çâk

Kendü gibi itmedür yârânı mu'tâd-1 rebâb Sâkıb Dede (Arı 2018: 159)

Inleyiş yayı/oku kemanda/yayda başsız, yüreği yaralı (bir hâlde) dostları rebaba alışkın hâle getirir.

Bu beyitte Sâkıb Dede (ö. 1735) oka benzettiği nâlenin dostları, iniltiye benzer sesler çıkaran rebaba alışkın hâle getirdiğini söylemiştir. Beyitte "tîr", "kemân" ve "rebâb"ın bir arada zikredilmesi ve "sîne-çâk" (yüreği yaralı) tabiri "tîr"in ok anlamıyla kullanılmış olabileceğini düşündürmekle birlikte "rebâb-tîr" 
birlikteliği kelimenin "yay” anlamına da bir gönderme olarak değerlendirilebilir. Diğer taraftan "tîr", "rebâb" ve "kemân" mûsikî terimi olarak ele alındığında beyitte bir keman-rebap karşılaştırmasının varlı̆̆ından söz edilebilir. Beyitte kemanın tellerine dokunduğunda iniltiye benzer sesler çıkaran yayın "mu'tâd-1 rebâb" (rebaba alışkın) olarak nitelenmesi rebabın Osmanlı mûsikîsinde kemandan daha eski bir saz olmasından kaynaklanmış olabilir.

Kadd-i ham-geştemi çeng etdi rebâb oldu gönül

Sîh-1 tîr-i gamına yandı kebâb oldu gönül Esrâr Dede (Horata 1998: 234)

Gönül bükülmüss boyumu eğri bü̈rrü/ç̧eng yapıp rebap oldu, gam okunun/ yayının şişine yanıp kebap oldu.

Esrâr Dede’ye (ö. 1796) ait bu beyitte rebabın oturarak diz üstünde çalınan bir saz oluşuna işaretle gönlün âşığın/şairin bükülmüş boyunu daha da eğerek rebap yaptı̆̆ ve gam okunun şişinde yanarak kebap olduğu söylenmiştir. Burada etkileyici ve hazin bir sesi olan rebabın "gam" ve "tîr" kelimeleriyle bir arada zikredilmesi "tîr"in "yay" anlamını da hatırlatmaktadır. Yine "çeng"in "rebâb" ve "tîr" ile ihâm-1 tenasüp oluşturacak biçimde kullanılması "tîr"in beyitte mûsikî terimi olarak anlamlandırılabileceğini göstermektedir. Bu durumda yayın rebap tellerine dokunduğunda çıkardığı hazin/yakıcı sesle gönlü kebap yaptığ1 söylenebilir. Beyitte rebap yayı şekil itibarıyla kebap şişiyle ilişkilendirilmiştir.

Mutrib idiyor câna eser tîr-i kemânun

Peykân-1 kazâ gamze-i dilber mi nedür bu ～Seyyid Vehbî (Dikmen 1991: 632)

Çalgıcı, kemanının yayı/oku gönle tesir ediyor. Kaza temreni mi, dilberin gamzesi midir, nedir bu?

Seyyid Vehbî’nin (ö. 1736) bu beytinde çalgıcının kemanına ait yayının gönle/cana tesir ettiği ve yayın bıraktığı tesir itibarıyla kaza temreni ve dilberin gamzesiyle eş olduğu ifade edilmiştir. "Tîr"in hem "ok" hem de "keman yayı" anlamına gelecek şekilde tevriyeli kullanıldığı beyitte yay; kemanın tellerine dokundurulduğunda çıkan etkileyici sesten dolayı, klasik Türk şiirinde okla ilgili kullanımlara da uygun biçimde, kaza temreni ve dilberin gamzesine benzetilmiştir. Ayrıca keman çalarken kemanın gövdesinin, dolayısıyla da yayın göğüs hizasına gelmesi kemanın yayının gönle/cana tesirini daha anlamlı kılmaktadır. 
Tîr-i müje nagamla deler bagrımı bu dem

Sîne kemân mı havf ki delik söylerim sana Lâzikîzâde Feyzullah Nâfiz (Demir 2017: 172)

Kirpikyayı/oku nağmelerle bağrımı deler bu dem; yazık, bağrım sinekemanı mı ki (ben) sana delikten bahsediyorum.

Lâzikîzâde Feyzullah Nâfiz’in (ö. 1767) yukarıdaki beytinde kirpiğe benzetilen keman yayı ile çalınan nağmelerin içe işlemesi, "tîr" kelimesinin ok anlamından dolayı "bağrı delmek" tabiriyle ifade edilmiş ve bu durum sinekemanının gövdesinde bulunan f delikleriyle ilişkilendirilmiştir. "Tîr"in hem "yay" hem de "ok" anlamıyla tevriyeli kulllanıldığı beyitte ok ile yaralanmış bağır görüntü itibarıyla üzerinde iki f deliği bulunan sinekemanına benzetilmiştir. Ayrıca "tîr" kelimesi yay anlamıyla "nagam" ve "sinekemân” ile tenasüp oluşturmaktadır.

El urup tîre her kemân ebrû

Elem ü hüzne kıldılar yâ hû S Şâkir Mehmed Efendi (Yanbal 2009: 487)

Her yay/keman kaş kirpiğelyaya el vurarak keder ve hüznü yok etti.

Şakir Mehmed Efendi’nin (ö. 1836) “Seyâhat-i Dil” başlıklı mesnevisinde yer alan ve aşk şehrinde vuku bulan latif bir hemgâmenin mûsikî unsurlarıyla tasvir edildiği birkaç beyitten biri olan yukarıdaki beyitte şekil itibarıyla yaya benzetilen kaşların istiare yoluyla okla ilişkilendirilen kirpiklere el vurarak sıkıntı ve kederi ortadan kaldırdığı söylenmiştir. Beyit tek başına değerlendirildiğinde "ok” ve "yay"ın klasik Türk şiirinin benzetme dünyasında akla ilk gelen karşılıklarının "kirpik" ve "kaş" olması dolayısıyla "tîr" ve "kemân" sevgilinin kirpiği ile kaşı olarak değerlendirilebilir. Bununla birlikte kendisinden önceki ve sonraki beyitlerin ${ }^{6}$ mûsikî ile ilgili olması, hatta her beyitte bir mûsikî aletinin söz konusu edilmesi beyitte "kemân"ın saz, "tîr"in de keman yayı olarak anlaşılabilecek şekilde tevriyeli kullanıldığını göstermektedir. Buna göre yayla çalınan kemanın çıkardığı seslerle sıkıntı ve kederi yok ettiği söylenebilir.

\footnotetext{
6 Reg-i tanbûra degdi mızrablar

Çıkdı evce sadâ-yı yâ Rablar

Nây ehl-i derûndan nâle

Her birin koydı dürlü ahvâle

Şâkir Mehmed Efendi (Yanbal 2009: 487)

Giryesin şaşırınca mûsikâr

Gam u endûha kıldı istigfâr

Şâkir Mehmed Efendi (Yanbal 2009: 487)
} 
Açılur ey kaşı ya sinemde zahmum gülleri

Bülbülâsâ tîrüni sen nagme-perdâz eylesen Gelibolulu Mustafa Âlî

(Aksoyak 2018: 859)

Ey kaşı yay olan sevgili! Sen yayını/okunu bülbül gibi şarkı söyleyen yapsan göğsümde yaramin gülleri açıllır.

Ucundaki kemiğe açılan delikler sayesinde atıldığında ses çıkaran ve "1slık çalan ok" (çavuş oku) olarak da bilinen bir ok türü bulunmaktadır (Göksu 2015: 126-133). Gelibolulu Mustafa Âlî’nin (ö. 1600) yukarıdaki beytinde bu ok türü söz konusu edilerek yay kaşlı sevgilinin okuna şarkı söyletmesi/ses çıkartarak atması durumunda âşığın göğsünde güle benzeyen yaralar açılacağı söylenmiştir. Bununla birlikte beyitte "tîr" olarak geçen okun şarkı söyleme/ses çıkarma yönüyle bülbüle benzetilmesi kelimenin yay anlamını da ister istemez akıllara getirmektedir. Hatta Gelibolulu Mustafa Âlî’nin bir başka beytinde yay anlamındaki “ok” kelimesini "kemânçe" ve "peşrev" ile bir arada zikretmesi kelimenin bilinçli bir şekilde yay anlamını da hatırlatacak şekilde tevriyeli kullnıldığı görüşünü desteklemektedir.?

Bagrum delinür tîr-i hasedden kaşun anup

Mutrib ele aldukça kemânını rebâbun Emrî (Saraç t.y.)

Çalgıcı kaşını anıp rebabın yayını eline aldıkça haset okundan bağrım delinir.

Rebap yayının, sevgilinin kaşı ile ilişkilendirildiği Emrî’ye (ö. 1575) ait bu beyitte sevgilinin kaşının mutrib tarafından anılmasınınâşıkta yarattı̆̆ı kıskançlı̆̆ın ok gibi yaralayıcı bir etki yaptı̆̆ı söylenmiştir. Rebap yayının "kemân” kelimesi ile ifade edildiği beyitte kanaatimizce "tîr" kelimesinin varlı̆̆ da tesadüf değildir. Yay anlamılla "mutrib", "kemân" ve "rebâb" ile ihâm-1 tenasübe sokulan "tîr" sözcüğünün beytin kurgusunda da etkili olduğu söylenebilir.

\section{Ok}

"Ok"un sözlüklerde yer alan anlamları şunlardır: 1. Yayla atılan, ucunda sivri bir demir bulunan ince ve kısa tahta çubuk. 2. Çatıya uzatılan direk. 3. Yılan. 4. Paylar ve toprak hisseleri üzerine -üleşmek için- atılan ok, çekilen kura. 5. 
Mirasta düşen pay. 6. Yön göstermek amacıyla belli yerlere konulabilen, oka benzer işaret. 7. At arabası, kağnı vb. araçlarda koşum hayvanlarının bağlandığı ağaç. 8. Araba, kağnı yapmakta kullanılan uzun, düz çam. 9. Kağnıda mazı üzerine boydan boya uzatılan yan ağaçları. 10. Bir dairede bir kirişin ortasında bu kirişi gören yayın ortasına indirilen doğru parçası. 11. Oklava. 12. Cirit, değnek. 13. Üzüm çardağına konulan uzun sırık. 14. Kâgir binalarda iki duvarın arasına çapraz konulan direkler. 15. Kalem gibi dümdüz olan bitki gövdesi. 16. Bir tarım aracı olarak tırmık. 17. Sürgü ya da tırmığı boyunduruğa bağlayan ağaç. 18. Tava. 19. Bir arazinin çizilerle belirlenmiş bölümlerinden her biri, sehim. 20. Bahçelerde fide yetiştirmek için ayrılmış bölüm. 21. Dil gibi uzun ve ensiz tarla parçası. 22. Sulamak için tarla içinde açılan ark. 23. Kabile teşkilatında küçük birlik. 24. Kabile örgütü, boy örgütü, soy, boy. 25. Hâl anlamına yakın anlamlı bir edat; vakit, zaman. 26. (Klasik Türk şiirinde) kaza, kader; sevgilinin gamzesi, kirpiği, cevri, cefası ve âşıkta uyandırdığı dert; âşığın âhı. 27. Keman ve kemençe yay1. ${ }^{8}$

Bir mûsikî unsuru olarak "Derleme Sözlügüu”nde "kemençe yayı" olarak belirtilen ok, "Turkish and English Lexicon"da ise "keman yayı" şeklinde yer almıştır. Okun klasik Türk şiirinde bu anlamıyla yer aldığı, tespit edilebilen, örneklerde de hem keman hem de kemençeyle bir arada kullanıldığ1 görülmüştür. Bununla birlikte okun, "tîr" in Türkçe karş1l lğ 1 olarak, keman ve kemençe dışında rebap, tambur gibi telli çalgıların yayları için de kullanıldığını söylemek mümkündür. Kelime bu anlamıla beyitlerde tevriye ve tenasüp/ihâm-1 tenasüp yoluyla yer bulmuştur.

Her perdesinde bir niçe bin nâle muhtefî

Her ok basışda itse ne var sad figân kemân Muvakkitzâde Pertev (Bektaş 2017: 466)

Her sesinde binlerce inleme gizlenmiş olan keman/yay her yay/ok basıldiğında yüz feryat etse ne olmuş?

8 Bu anlamlar için bkz.: Besim Atalay, Dîvânu Lûgat-it-Türk Tercümesi, TDK Yayınları, Ankara 1998, C. I, s. 37, 48.; Sir James W. Redhouse, Turkish And English Lrxicon New Edition, Çağrı Yayınları, İstanbul 2006, s. 260.; Türkiye'de Halk Ağzindan Derleme Sözlüğü, TDK Yayınları, Ankara 1993, C. IX, s. 3273-3274.; http://sozluk.gov.tr. (E.T. 23.06.2019).; Şükrü Halûk Akalın-Recep Toparlı vd, Türkçe Sözlük, TDK Yayınları, Ankara 2011, s. 1790-1791.; Yaşar Çağbayır, Ötüken Türkçe Sözlük, Ötüken Neşriyat, İstanbul 2007, C. IV, s. 3595-3596.; Uğur Baydu, Müzik Terimleri Sözlüğ̈̈, Akıl Fikir Yayınları, İstanbul 2016, s. 301. 
Muvakkitzâde Muhammed Pertev'e (ö. 1807/1808) ait bu beyitte her sesi inlemeyi andıran kemanın, yayı tellerine her dokunduğunda âdeta feryat ettiği söylenmiştir. Beyitte keman yayı anlamındaki "ok" ile "perde" ve "kemân" kelimeleri tenasüp oluşturacak biçimde bir arada kullanılmıştır.

Eline aldı kemânçe okını mutrıb-ı bezm

İtdi her pîş-revi tîr-sıfat cânuma kâr Nevîzâde Atâyî (Karaköse 2017)

Meclisin çalgıcısı eline kemençe okunu/yayını aldı, her peşrevi ok gibi canıma işledi.

Nevîzâde Atâyî (ö. 1635) bu beytinde meclisin çalgıcısının kemençe yayıyla icra ettiği peşrevlerin ruha etkisini okun yaralayıcılığıyla ifade etmiştir. "Kemânçe-ok-mutrib-pîşrev" kelimeleriyle tenasüp oluşturulan beyitte "tîr"in ok anlamıyla kullanılması kelimenin telli çalgılarda kullanılan yay anlamına da bir gönderme olarak değerlendirilebilir.

Yine âvâz-1 kemânçe dile te'sîr itdi

Sînede ok gibi her pîş-revi yir itdi Gelibolulu Mustafa Âlî

(Aksoyak 2018: 439)

Kemençe sesi yine gönle tesir etti, her peşrevi göğüste/yürekte ok/yay gibi yer etti.

Gelibolulu Mustafa Âlî de yukarıdaki beytinde etkileyici bir sesi bulunan kemençeyle çalınan peşrevlerin etkisini oka benzetmiştir. Beyitte kemençe yayı doğrudan söz konusu edilmemiştir. Bununla birlikte mûsikî ekseninde kurulmuş bu beytin kelime kadrosunda yer alan "ok" kelimesinin kemençe yayı anlamıyla ihâm-1 tenasüp oluşturacak biçimde özellikle tercih edildiği söylenebilir.

İrince feyz-i irşâdı kemânçe târını kırdı

Okın atdı kemânın yadsı ya‘ni Zühre-i zehrâNevîzâde Atâyî

(Karaköse 2017)

Irşadın ilerlemesi tamamlanınca kemençe telini kırdl, yani parlak Zühre okunu yayın gererek attı.

Nevîzâde Atâŷ̂’ye ait mirâciyye kasidesinde yer alan bu beyitte Cebrail rehberliğinde yapılan yolculuğun tamamlanmasıyla kemençenin telini kırdı̆̆ söylenmiş, bu durum da Zühre'nin ok atarken kemanını gererek atmasına 
benzetilmiştir. Bu beyitte de kemençe yayı söz konusu edilmemekle birlikte kemençe-ok birlikteliği akıllara kelimenin yay anlamını da getirmektedir.

\section{Sonuç}

"Tîr" ve onun Türkçe karşıllğı olan "ok" kelimeleri klasik Türk şiirinde genellikle bir silah unsuru olarak yer almaktadır. "Tîrin/okun" bu yaygın kullanımı dışında şiir metinlerinde geçen fakat lûgatların büyük çoğunluğunda yer almayan "keman, kemençe, rebap gibi bazı telli çalgıların çalınması için kullanılan âlet/ yay" anlamı da bulunmaktadır ki, bu anlam metinlerde özellikle tevriye yoluyla oluşturulan çok anlamlı yapı içerisinde gözden kaçırılabilmektedir. Söz konusu kelimelerin bu farklı kullanımına dikkat çekmek üzere kaleme alınan bu makalede verilen örnek beyitlerde "tîr/ok" genellikle tevriye, tenasüp/ihâm-1 tenasüp, teşbih ve istiare yoluyla yer almıştır. Benzetmeye dayalı sanatlar olan teşbih ve istiare yapılırken "tîr/ok" çoğunlukla klasik Türk şiirindeki yaygın kullanımıyla da mütenasip bir biçimde, gamze, bakış, kirpik, kebap şişi, temren ve bülbüle benzetilmiştir. Benzetme yönü ise genellikle onun mûsikî aletlerinin tellerine dokunduğunda çıkardığı sesin etkileyiciliği/yaralayıcılı̆̆ıdır. Bazı örneklerde ise şeklî benzerlik (kebap şişi ve kirpik gibi) gözetilmiştir. Yapılacak metin çözümlemelerinde bu kelimelerin söz konusu anlamının da dikkate alınması yer aldıkları şiir metinlerinin daha doğru anlaşılmasını sağlayacaktır. Ayrıca bu çalışma, çok anlamlı bir yapı arz eden, klasik Türk şiiri metinlerinde yer alan kelimelere daha önce gözden kaçırılmış olabilecek farklı anlamlarının bulunması ihtimaliyle dikkatle yaklaşılması gerektiğini bir kez daha göstermektedir. 


\section{Kaynakça}

Ahmed Eflâkî. (2006), Ariflerin Menkıbeleri, çev.: Tahsin Yazıc1, İstanbul: Kabalcı Yayınları. Akalın, Şükrü H.-Toparlı, Recep vd. (2011), Türkçe Sözlük, Ankara: TDK Yayınları.

Aksoyak, İsmail H. (2018), Gelibolulu Mustafa Âl̂̀ Dîvânı, http://ekitap.kulturturizm.gov.tr/ Eklenti/58695,gelibolulu-mustafa-ali-divanipdf.pdf?0 (E.T. 10.06.2019)

Arı, Ahmet (2018), Sâkıb Dede Dîvânı, http://ekitap.kulturturizm.gov.tr/Eklenti/59860,sakibdede-divanipdf.pdf?0 (E.T. 01.06.2019).

Atalay, Besim (1998), Dîvânu Lûgat-it-Türk Tercümesi, C. I, Ankara: TDK Yayınları.

Aydemir, Yaşar (2018), Ramazan Behiştî Dîvânı, http://ekitap.kulturturizm.gov.tr/ Eklenti/56445,ramazan-behisti-divanipdf.pdf?0

(E.T. 01.06.2019).

Baydu, Uğur (2016), Müzik Terimleri Sözlüğü, İstanbul: Akıl Fikir Yayınları.

Bektaş, Ekrem (2017), Muvakkit-zâde Muhammed Pertev Dîvânı, http://ekitap.kulturturizm. gov.tr/Eklenti/55973,pertev-divanipdf.pdf?0 (E.T. 10.06.2019).

Çağbayır, Yaşar (2007), Ötüken Türkçe Sözlük, C. IV-V., İstanbul: Ötüken Neşriyat.

Demir, Hiclal (2017), Lâzikîzâde Feyzullah Nâfiz ve Dîvânı, http://ekitap.kulturturizm.gov.tr/ Eklenti/54126,53959lazikizade-feyzullah-nafizdivanpdfpdf.pdf?0 (E.T. 10.06.2019).

Devellioğlu, Ferit (1999), Osmanlıca-Türkçe Lûgat, Ankara: Aydın Kitabevi.

Dikmen, Hamit (1991). Seyyid Vehbî Ve Divanının Karşılaştırmalı Metni. Yayınlanmamış Doktora Tezi. Ankara: Ankara Üniversitesi SBE.

Göksu, Erkan (2015), Türk Kültüründe Silah, İstanbul: Ötüken Neşriyat.

Horata, Osman (1998), Esrâr Dede Hayatı-Eserleri-Şiir Dünyası ve Dîvânı, Ankara: T.C. Kültür Bakanlığı Yayınları.

Hüseyin Remzi (H. 1305), Lûgat-ı Remzî, C. I, İstanbul: Matbaa-i Hüseyin Remzi.

Kanar, Mehmet (1993), Büyük Farsça-Türkçe Sözlük, İstanbul: Birim Yayınları.

Karaköse, Saadet (2017), Nev'î-zâde Atâŷ̂ Dîvânı, http://ekitap.kulturturizm.gov.tr/ Eklenti/55734,nevi-zade-atayi-divanipdf.pdf?0 (E.T. 02.06.2019).

Mütercim Âsım (2009), Burhân-ı Katı, İstanbul: TDK Yayyınları.

Okcu, Naci (2011), Şeyh Gâlib Dîvânı Hayatı-Edeb̂̂ Kişiliği-Eserleri-Şiirlerinin Umûmî Tahlîli, Ankara: TDVY.

Olgun, İbrahim-Drahşan, Cemşit (2005), Farsça-Türkçe Sözlük, Ankara: Murat Kitabevi.

Şemseddin Sami (2006), Kâmûs-ı Türkî, İstanbul: Çağrı Yayınları.

Redhouse J.W. (1863), Lûgat-i Osmânîyye, İstanbul: Matbaa-i Âmire. 
Redhouse J.W. (2006), Türkish And English Lexicon New Edition, İstanbul: Çağrı Yayınları.

Saraç, M.A.Yekta (t.y.), Emrî Dîvânı, http://ekitap.kulturturizm.gov.tr/ Eklenti/10607,emridivanipdf.pdf?0. (E.T. 22.06.2019).

Steingass, F. (2005), A Comprehensive Persian-English Dictionary, İstanbul: Çağrı Yayınları.

Tarlan, Ali N. (1992), Ahmet Paşa Divanı, Ankara: Akçağ Yayınları.

Türkiye'de Halk A ğzından Derleme Sözlü̆̆̈̈, (1993), C. IX, Ankara: TDK Yayınları.

Türkiye'de Halk Ă̆zından Derleme Sözlüğ̈̈, http://sozluk.gov.tr. (E.T. 23.06.2019).

Uygun, M.Nuri (2007), Mevlânâ Celâleddîn-i Rûmî̀nin Eserlerinde Ve Tasavvuf Anlayışında “Rebap”, İSTEM, S. 10, 113-126.

Yanbal, Semra (2009), Şâkir Mehmed Efendi Divânı (Metin-İnceleme), Yayınlanmamış Yüksek Lisans Tezi, Sivas: Cumhuriyet Üniversitesi SBE.

Ziya Şükûn (1984), Gencinei Güftar Ferheng-i Ziya, C. I, İstanbul: MEB Yayınları. 